\title{
LA TRAVESURA DE LA ULTRACOMEDIA
}

José Luis Vila Leirós

Universidade de Santiago de Compostela

Hace un tiempo que Jordi Costa viene hablando de «nueva comedia» o "posthumor» para referirse al «humor de chistes que no hacen gracia» y «no provoca la carcajada sino la incomodidad» ${ }^{1}$. En nuestro país muchos de los que podríamos llamar representantes de este humor tienen en su formación algún vínculo con las Bellas Artes: sucede al menos con Carlo Padial y Didac Alcaraz (que estudiaron en la escuela Massana de Barcelona), con los componentes de La hora chanante y Muchachada Nuí (que lo hicieron en la facultad de Bellas Artes de Cuenca) y con Miguel Noguera (que cursó Bellas Artes en la Universidad de Barcelona). Las enormes pasiones que desatan (se sabe que Doña Leticia acude en secreto a las presentaciones de Noguera) justifica hasta una nota de tendencias en una revista académica que en esto sigue los pasos de los muchos comentarios en la prensa.

Sus shows se multiplican por doquier, repartidos por la geografía física y por esa nueva geografía digital que conforman el YouTube, Vimeo y muchos más. Ahora bien, ¿influye de alguna manera el contacto con las Bellas Artes en la concepción que estos «posthumoristas» tienen de lo cómico y en lo que aportan a esta «nueva comedia»? Si nos centramos en cómo confluyen todos estos factores en la figura de Miguel Noguera, podemos decir que sí. "Creo -comenta el canario-que la base de lo que hago la formé en Bellas Artes. En todo caso, como he dicho muchas veces, apenas pienso en la comedia como tal, como género. Ahí hay que trazar una distinción un poco rara [...]"2. Y, abordando el mismo tema, añade:
Tras haberle dado $x$ vueltas al tema, en este momento pienso que el núcleo de este conflicto de identidad (humorista-no humorista) se compone de dos elementos: A: Mi formación es artística, aprendí a pensar mi producción como "arte contemporáneo", no como humor, y eso sigue así en mi cabeza. [...] B: El hecho inevitable de que por mucho que intentes expandir o abrir el campo de lo cómico aquel que hace humor siempre será considerado como alguien que dice de si "estoy aquí para haceros reír, soy la sal de la vida, tenéis derecho a reclamar eso de mi" y yo no quiero asumir ese rol de forma directa ${ }^{3}$.

Lo cómico sufre aquí un gran cambio:

Si es cierto que en el show me comporto de forma bufonesca y en mi día a día siempre hago bromitas con amigos y familiares, [...] pero por otro lado las cosas que anoto son mayoritariamente tensiones formales, no gags ni cosas que me hagan gracia, es algo más cercano a la pintura, a la escultura o la poesía, esas tensiones formales suelen resultar más o menos cómicas, por lo gráficas que son, y porque suele haber como un "clic", una tontería, una mezcla sorpresiva, o una inmediatez, algo bobo y complejo al mismo tiempo, y casi siempre abrupto. [De esta forma] 'hacer reír', la comedia, el 'buen humor' del cómico, el humor como objetivo no me atraen y de hecho me repelen. Por eso me resulta dificil definir mi relación con la comedia». De esto podemos colegir que son las «tensiones formales» lo que atrae a Noguera, «[...] no tanto lo gracioso que pueda resultar sino el forzamiento formal en sí mismo, el permitirse hacerlo y que no se haga en nombre del humor ni de un arte serio 4 .

¿En dónde reside el núcleo del problema? ¿Qué eluden este humor y esta comedia que 
parecen querer esquivarse a sí mismos? Una posible respuesta estaría en la irrupción de ese "click», sobre todo cuando encuentra nuevas grietas humorísticas desde las cuales reír:

No el humor común, ese que todos entendemos y nos une -que es el que se le presupone al humorista-, sino el humor que nos separa. El humor de la discordia. El humor como forma de ser, como venganza ante el orden simbólico, el humor que se ríe del consenso, encuentra las grietas y asi construye un consenso minoritario ${ }^{5}$.

Semejante recurso nos sitúa en un lugar, podríamos decir, mucho más violento ${ }^{6}$. Este lugar supone una separación frente al sentido común y la forma en que normalmente vemos el humor y lo cómico, un refugio alegre frente a aquello que nos dice de lo que debemos o no reírnos ${ }^{7}$. De aquí brota esa «venganza» ante un «orden simbólico» que siempre presiona la risa en la dirección de ese consenso y ese humor que homogeneizan sin saber hasta qué punto aplanan nuestras ideas del mundo. Al fin y al cabo, ¿no es de ideas de lo que nos habla Noguera?
La grieta del «click» separa un humor moralmente travieso del que no lo es, la tensión de la experimentación se escurre entre las dos manos del macro-consenso generando un nuevo espacio minoritario. Una mano es la del humor común (aquella que dice de qué podemos reirnos), la otra es la del arte serio (aquella que dice de qué no podemos reirnos). La experimentación formal, al atravesar estos dos consensos, convierte en su máxima virtud ser un nuevo "a través» de esta nueva comedia que es travesura otra vez.

Así pues, al menos en el caso de Noguera, cabría hablar menos de "posthumor» que de «humor travieso», humor que se ríe tanto de lo que podemos reirnos como de lo que no, agresión cómica que amputa las manos de ese orden simbólico que fuerza una unión no deseada por ambos. Humor que se escurre y se desliza, humor de combate, humor que atraviesa: humor violencia. Ultrahumor o ultracomedia: la travesura ultraviolenta.

\section{NOTAS}

${ }^{1}$ Diario de Sevilla. El triunfo del 'posthumor' [en línea]. http://www. diariodesevilla.es/article/ocio/843201/ triunfo/posthumor.html. [Consulta: 29 de junio de 2014]

${ }^{2} \mathrm{M}$. Noguera, Re: Información para un artículo [correo electrónico]. 25 de junio de 2014 [fecha de consulta: 2 de julio de 2014]. Comunicación interna.

${ }^{3}$ Citado en M. Cebrián, «"El humor como venganza ante el orden simbólico": las ideas y ultrashows de Miguel Noguera» (inédito enviado por Noguera vía e-mail), 2013.
${ }^{4} \mathrm{M}$. Noguera, ibid.

${ }^{5}$ M. Cebrián, ibíd.

${ }^{6}$ La tarea sería explorar el vínculo entre esta violencia y obras de Noguera como Ultraviolencia (Blackie Books, 2011), así como el "mundo violencia" del que habla en ocasiones (¿no cabría explorar también este Ultra?): «Muchas de mis anotaciones rescatan objetos que simplemente me atraen y quiero tener presentes, afectos formales, objetos amigos, una especie de minimalismo sacro, como ciencia ficción mezclada con el medievo, un mundo sobrio de combate, mundo violencia lo \|lamo [...].» [Las cursivas son nuestras]
(Youtube. Qué es Idea? Miguel Noguera y Soy Cuyano / VII Jornadas Permanentes de Pensamiento Experimental. [5 de Noviembre de 2013] [Archivo de video] Obtenido de https://www. youtube.com/watch? $v=$ Dfsa3fQCv10 [Consulta: 29 de junio de 2014]).

${ }^{7}$ «Esto que hago nace de lo más marginal, lo que ahora me da de comer se basa en lo más intrascendente pero, por favor, no penséis mal, es un regalo que así sea, esto es lo único que me distingue, lo que restablece mi orgullo dañado y en cierto modo mi venganza» (Ibid). 